\title{
A Systematic Review to Guide Future Efforts in the Determination of Genetic Causes of Pregnancy Loss
}

\author{
Andrew Z. Carey ${ }^{1}$, Nathan R. Blue ${ }^{1,2}$, Michael W. Varner ${ }^{1,2}$, Jessica M. Page ${ }^{1,2}$, \\ Nathorn Chaiyakunapruk ${ }^{3,4}$, Aaron R. Quinlan ${ }^{5,6,7}$, D. Ware Branch ${ }^{1,2}$, Robert M. Silver ${ }^{1,2}$ \\ and Tsegaselassie Workalemahu ${ }^{1 *}$ \\ ${ }^{1}$ Department of Obstetrics \& Gynecology, University of Utah Health, Salt Lake City, UT, United States, ${ }^{2}$ Department of \\ Obstetrics and Gynecology, Intermountain Healthcare, Salt Lake City, UT, United States, ${ }^{3}$ Department of Pharmacotherapy, \\ College of Pharmacy, University of Utah, Salt Lake City, UT, United States, ${ }^{4}$ School of Pharmacy, Monash University \\ Malaysia, Subang Jaya, Malaysia, ${ }^{5}$ Department of Human Genetics, University of Utah, Salt Lake City, UT, United States, \\ ${ }^{6}$ Utah Center for Genetic Discovery, University of Utah, Salt Lake City, UT, United States, ${ }^{7}$ Department of Biomedical \\ Informatics, University of Utah, Salt Lake City, UT, United States
}

\section{OPEN ACCESS}

Edited by: Carlo Ticconi,

Policlinico Tor Vergata, Italy

Reviewed by: Nicoletta Di Simone,

Humanitas University, Italy

Caterina Exacoustos,

Università di Roma Tor Vergata, Italy

*Correspondence:

Tsegaselassie Workalemahu tseloti@gmail.com

Specialty section:

This article was submitted to

Gynecology,

a section of the journal

Frontiers in Reproductive Health

Received: 04 September 2021 Accepted: 10 November 2021 Published: 15 December 2021

Citation:

Carey AZ, Blue NR, Varner MW

Page JM, Chaiyakunapruk N, Quinlan AR, Branch DW, Silver RM

and Workalemahu T (2021) A

Systematic Review to Guide Future Efforts in the Determination of Genetic

Causes of Pregnancy Loss.

Front. Reprod. Health 3:770517.

doi: 10.3389/frph.2021.770517
Background: Pregnancy loss is the most common obstetric complication occurring in almost $30 \%$ of conceptions overall and in $12-14 \%$ of clinically recognized pregnancies. Pregnancy loss has strong genetic underpinnings, and despite this consensus, our understanding of its genetic causes remains limited. We conducted a systematic review of genetic factors in pregnancy loss to identify strategies to guide future research.

Methods: To synthesize data from population-based association studies on genetics of pregnancy loss, we searched PubMed for relevant articles published between 01/01/2000-01/01/2020. We excluded review articles, case studies, studies with limited sample sizes to detect associations $(N<4)$, descriptive studies, commentaries, and studies with non-genetic etiologies. Studies were classified based on developmental periods in gestation to synthesize data across various developmental epochs.

Results: Our search yielded 580 potential titles with 107 (18\%) eligible after title/abstract review. Of these, 54 (50\%) were selected for systematic review after full-text review. These studies examined either early pregnancy loss ( $n=9$ [17\%]), pregnancy loss $>20$ weeks' gestation ( $n=10[18 \%])$, recurrent pregnancy loss ( $n=32$ [59\%]), unclassified pregnancy loss ( $n=3[4 \%])$ as their primary outcomes. Multiple genetic pathways that are essential for embryonic/fetal survival as well as human development were identified.

Conclusion: Several genetic pathways may play a role in pregnancy loss across developmental periods in gestation. Systematic evaluation of pregnancy loss across developmental epochs, utilizing whole genome sequencing in families may further elucidate causal genetic mechanisms and identify other pathways critical for embryonic/fetal survival.

Keywords: early pregnancy loss, recurrent pregnancy loss, stillbirth, fetal death, genetics 


\section{HIGHLIGHTS}

- The etiologies of PL and its genetic causes are poorly understood.

- Limited number of studies identified genetic pathways essential for PL.

- Genetic pathways are essential for embryonic/fetal survival and human development.

- Future research strategies require systematic evaluation of PL in families.

\section{INTRODUCTION}

Pregnancy loss is the most common obstetric complication occurring in about $30 \%$ of conceptions (1). Approximately 10$28 \%$ of all clinically recognized pregnancies result in losses (2); of these, most occur prior to the second trimester. In the United States, losses after 20 weeks' gestation occur 1 in 160 pregnancies (3). The risk of pregnancy loss increases with a previous loss (4), suggesting that genetics may play role in families experiencing recurrent losses. Pregnancy loss recurs in about $1-2 \%$ of couples who are trying to conceive (5), and about $25 \%$ of women attempting pregnancy experience at least one loss (6). Approximately, 50\% of recurrent pregnancy loss (RPL) cases are idiopathic (i.e., without any known etiologies) (7).

Genetic abnormalities (chromosomal and single-gene disorders) in the conceptus are an established etiology of pregnancy loss (8). Fetal or placental karyotype analyses allow detection of aneuploidy (chromosomal abnormalities) in 55\% of first trimester losses, 35\% of second trimester losses, and 7\% of losses $>20$ weeks' gestation (9), confirming the higher rate of genetic factors contributing to losses in earlier gestation (10). However, genetic causes of losses $>20$ weeks' gestation may not be identified by karyotype (3). Recent studies in a large cohort of losses $>20$ weeks' gestation identified aneuploidy or pathogenic copy number changes as genetic causes of losses $>20$ weeks' gestation in $44(9.5 \%)$ cases using chromosomal microarray analysis (3) and single-gene pathogenic variants in 13 genes ( 7 previously identified and 6 strong candidates) causing 15 (6.1\%) losses $>20$ weeks' gestation using whole exome sequencing (WES) (11). Although findings from these studies may guide future research into mechanisms of pregnancy loss, they do not adequately facilitate clinical efforts to genetically screen losses across different developmental epochs $(10,12)$. Studies that examine DNA from products of conception, as well as the parent-offspring trio (maternal, paternal and fetal) samples, will be critical to identify causal variants and clinically significant genes. In addition, studies that identify pathways that are essential for normal and abnormal pregnancy may facilitate the discovery of novel therapeutic targets to improve pregnancy outcomes.

With the advent of next-generation sequencing (NGS), studies in the past 20 years have identified genetic pathways that are essential for in utero survival. In particular, some studies have shown increased likelihood of a genetic cause in early pregnancy (13), while challenges (e.g., accessibility, maternal cell contamination) remain when assessing biospecimen in products of conception from early losses. Furthermore, inconsistencies in categorizing pregnancy loss by gestational age have been noted by others (14). Using suggested standardized definitions of pregnancy loss, we underscore the importance of categorizing losses with regard to gestational age and developmental stage at the time of loss in future studies $(10,14)$. We conducted a systematic review to highlight genetic/multi-omic studies of pregnancy loss conducted between 2000 and 2020 and discussed key strategies to guide future relevant research efforts. Studies were classified based on developmental periods in gestation to synthesize data across various developmental epochs, allow classification by stage and etiology of loss (14) and identify common pathways (15).

\section{MATERIALS AND METHODS}

\section{Search Strategy}

Previously published manuscripts on pregnancy loss were identified through a literature search using PubMed. The search criteria included keywords and Medical Subject Headings terms; "pregnancy loss," "stillbirth," "fetal death" or "fetal death," and "placenta."

\section{Study Selection}

Manuscripts were eligible if they were full-text articles written in English, published between January 01, 2000 and January 01,2020 , and conducted in humans or human cell lines. We chose a search period of the last 20 years in order to identify publications that potentially utilized NGS approaches during a time when accessibility to the technologies increased. In addition, we incorporated publications investigating the placenta as there is likely a genetic contribution to placental insufficiency in some pregnancy losses $(16,17)$. Since the placenta is genetically similar to the fetus, it allows examination of both maternal and paternal contributions, as well as de novo mutations to pregnancy loss. We excluded case studies, studies with very small sample sizes $(n<4)$, descriptive articles or commentaries, infertility/nonspontaneous abortion studies and studies with non-genetic etiologies. Systematic review articles that met search criteria were further explored for relevant studies referenced therein.

\section{Pregnancy Outcome Classification Based on Developmental Epochs}

Studies report their primary outcomes over a broad range of gestational ages [e.g., conventional definitions of stillbirth and Early Pregnancy Loss (EPL)], therefore, in the present review, we aimed to summarize studies by the pregnancy outcomes: EPL (including peri-implantational, pre-embryonic, embryonic, fetal death and early fetal death), late fetal death and losses $>20$ weeks' gestation, unclassified fetal death (losses assessed across gestation) and RPL. RPL is most commonly defined as $\geq 3$ losses with $\leq 1$ intervening live birth (5), however, we included studies that defined RPL as $\geq 2$ losses. The recommended classifications allow evaluation across various developmental epochs, classifying losses by stage and etiology of loss (14) to help identify common pathways (15). Furthermore, the classifications may identify studies that report genetic factors with different mechanisms, 
e.g., genes essential for embryonic lethality and functional genes essential for human development (e.g., cardiomyopathy).

\section{Study Summarization}

In this systematic review, we summarized the studies according to PubMed ID, first author last name and initial, year of publication, pregnancy loss outcome, predictor(s), method of assessment or study design, sample size, and tissue. We provide studies that identified candidate genes with functional pathways. For studies that did not report specific pathways, we conducted an Online Mendelian Inheritance in Man (OMIM) search to identify the roles of the reported genes in disease or functional pathways. Finally, we focused our discussion toward studies that report findings based on genetic factors that are likely causal (e.g., single-gene, autosomal and/or recessive de novo or inherited mutations, "intolerome," copy number variations [CNVs], single nucleotide polymorphisms [SNPs]) (13). We summarized multiomic studies, e.g., studies based on proteins and methylated genes that have different mechanisms than single-gene mutations or CNVs. The literature search was cross-examined by Authors. All conflicts were discussed and resolved before proceeding to systematic review.

\section{Systematic Review}

The PRISMA 2020 checklist was utilized to ensure the manuscript conformed to the systematic review definition. Of note, this study has not been registered with a specific review protocol. There are no randomized clinical trials on genetics of pregnancy loss. Risk of bias was not assessed, principle summary measures were not utilized, and synthesis of data for a metaanalysis was not performed.

\section{RESULTS}

\section{Screened Studies Selected for Systematic Review}

Our search yielded 580 potential records. The PRISMA flow diagram is provided in Figure 1. After title and abstract review, 38 records were excluded after additional filters for articles that are not full text, based on non-human studies, and not identified as English articles. After title/abstract review, additional 446 records were excluded because they were either descriptive/commentaries, studies with small sample size $(n<4)$, qualitative studies, systematic or comprehensive reviews, studies based on infertility and non-spontaneous abortion, or ambiguous with critical information missing. After full-text review, 53 fulltext articles that were based on non-genetic factors associated with pregnancy were excluded. In the present study, we included 54 studies that reported findings based on genetic/multi-omic etiologies involved in pregnancy loss.

\section{Genetic Factors Associated With EPL}

Nine studies (17\%) examined genetic factors in relation to EPL (Table 1). Most of the studies identified dysregulated miRNAs, epigenetic regulators which may have important role in placental development and function. The largest of these, with sample size reaching 105 participants, showed that miR-378a-3p is downregulated in early pregnancy loss $(n=50)$ compared with normal $(n=55)$ decidua (24). Hosseini et al. detected other dysregulated microRNAs (e.g., miR-135a) in maternal plasma and villous cells of women $(n=16)$ who had EPL, but the comparison group were women $(n=8)$ who underwent abortions (23). Using endocervical specimens collected prior to EPL $(n=20)$, altered protein expression patterns of extra villous trophoblast (EVT), which plays a role in proper implantation and placentation, were detected in cases compared to controls (21). The authors' ability to obtain EVT cells early from ongoing pregnancies and determine the eventual pregnancy loss occurrences may have allowed opportunities to discover novel biomarkers through global analytic approaches (21).

\section{Genetic Factors Associated With Losses $>20$ Weeks' Gestation}

Since a standardized definition of stillbirth has not been agreed upon, studies examining loss $>20$ weeks' gestation were lumped together and classified based on their specific cutoffs. One study examined self-reported miscarriage or stillbirth as the primary outcome over a broad range of gestational ages and 10 studies (18\%) examined losses $>20$ weeks' gestation as the primary outcome (Table 2). Of these 10 studies, cutoffs of 20, 22, 23, 24, and 32 weeks were utilized (Table 2). Seven studies examined the associations of genes involved in maternal thrombophilia with losses $>20$ weeks' gestation. The largest of these, with sample size reaching 1,830 participants, performed a candidate gene analysis (30). The only positive association was with maternal homozygous SNP in FVL (Factor V Leiden) gene (2/488 [0.4\%] vs. $1 / 1380[0.0046 \%] ; O R=87.4 ; 95 \%$ confidence interval [95\%CI]: 7.9-970.9). The investigators concluded that these heritable thrombophilia genetic markers were not associated with losses $>20$ weeks' gestation. In another candidate gene study, pregnancy loss $>22$ weeks' gestation was associated with carriers $(n=96)$ of allele A of rs1800783 eNOS (endothelial nitric oxide synthase 3 ) gene in placental tissue. The eNOS gene may be critical for pathways involved in placental growth (28). Furthermore, a genome-wide analysis using high-resolution Illumina SNP arrays identified 24 putative novel CNVs in placental and fetal samples $(n=54)$ (27). Using a larger study with similar methodology, Reddy et al. detected normal, abnormal (pathogenic), and variants of unknown significance CNVs in 396 (74.4\%) samples from pregnancy loss > 20 weeks' gestation (including samples with anomalies) (3). The remainder of the studies examining losses $>20$ weeks' gestation utilized other techniques such as quantitative reverse transcriptase polymerase chain reaction (qRT-PCR), immunohistochemistry, and Western blot.

\section{Genetic Factors Associated With RPL}

Thirty-two studies (59\%) examined RPL, including preembryonic, embryonic, and fetal losses, as the primary outcomes. There was variation in the definition of RPL across studies, with some using a minimum of two losses $(34,35)$ and others using a minimum of three $(17,36-42)$ (Table 3$)$. The majority of RPL studies were hypothesis-based, i.e., conducted a candidate gene approach to examine SNPs in selected genes, a priori, and 


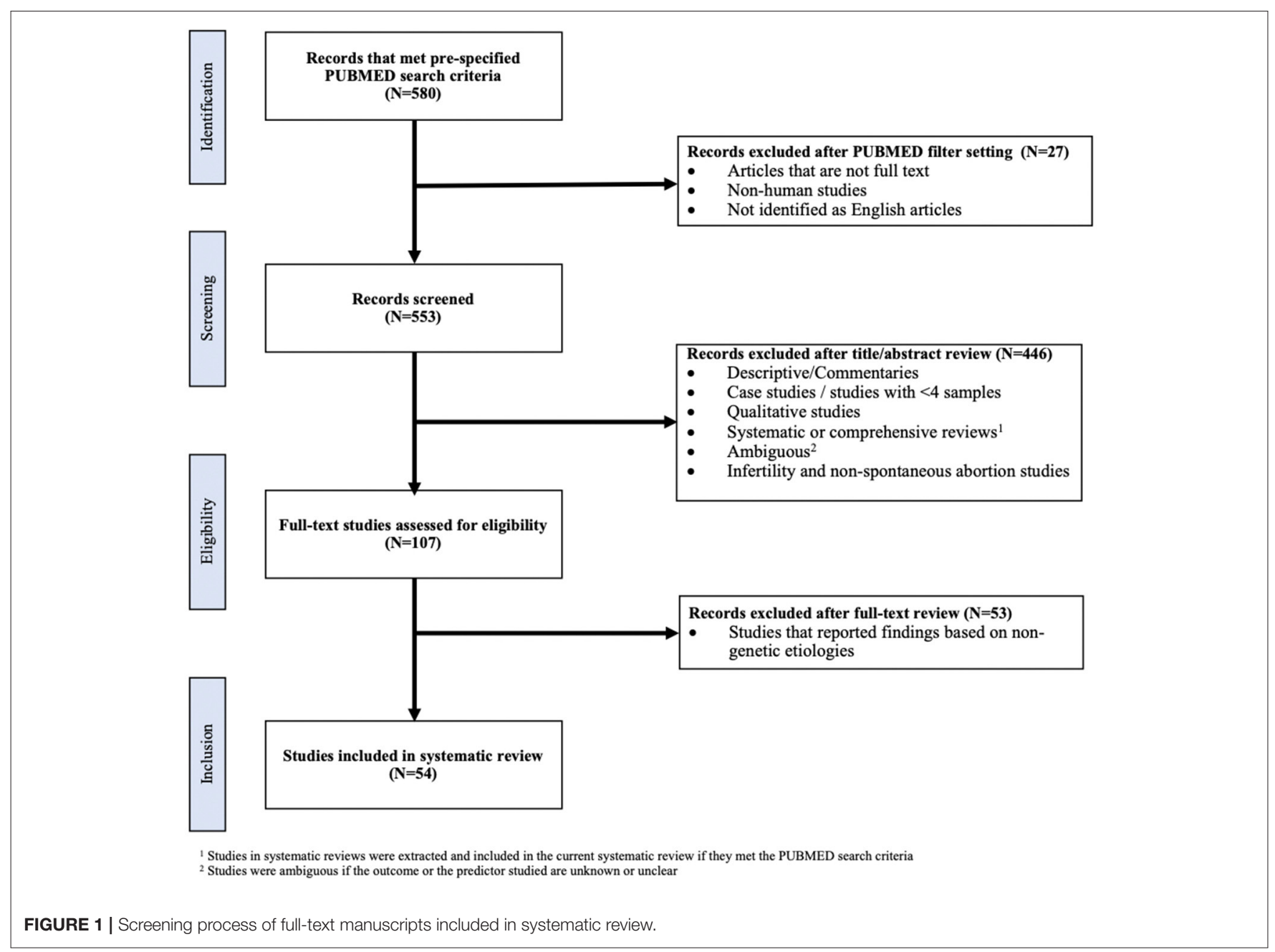

with plausible pathophysiologic pathways. Haplotype analysis conducted by Rogenhofer et al. showed that maternal blood M2 haplotype carriers with RPL $(n=100)$ in ANXA5, annexin 5 gene involved in coagulation, had a 3.4-fold increased RPL risk compared to controls $(n=500)$ and a 2.1 -fold increased RPL risk compared to randomly selected population controls $(n=533)$ (47). SNP-prevalence analysis conducted by Jin et al. showed RPL cases $(n=112)$ carried the rs $2249825 \mathrm{G}$ allele in HMGB1 (high mobility group box 1) gene in maternal whole blood more frequently than controls $(n=118)$ (48). Seyedhassani et al. compared the frequency of mutations in $B A X$ gene, a pro-apoptotic gene, among RPL women $(n=67)$ and controls $(n=70)$ and showed associations between A(-179)G mutation in the BAX promoter and RPL (41). Quintero-Ronderos et al. sequenced the complete coding region of $T H B D$, the endothelial cell receptor for thrombin gene, in women affected by RPL $(n=262)$ and showed THBD-p.Trp153Gly mutation might be related to RPL (54). Lastly, Masini et al. analyzed the genotype and allele frequencies of thrombin-activatable fibrinolysis inhibitor (TAFI) SNPs among women with $(n=86)$ and without $(n=72)$ RPL. Genotype and allele frequencies of TAFI +505 and +1583 SNPs were significantly different in women with RPL compared to controls (38).

Genome-wide association studies of RPL were also conducted to highlight genetic variants with relevant functional pathways. For example, Kasak et al. examined placental and parental genome-wide CNV profiles of idiopathic RPL trios $(n=25$ parental blood, $n=13$ placental $)$ and duos $(n=8$ maternal blood, $\mathrm{n}=9$ placental), and detected CNVs in NUP98 and MTRR genes (7). NUP98 (Nucleoporin 98 And 96 Precursor) and MTRR (5-Methyltetrahydrofolate-Homocysteine Methyltransferase Reductase) genes are implicated in embryonic stem cell development and folate metabolism, respectively (7). Another genome-wide association study was reported by $\mathrm{Yu}$ et al. (31) but the study identified DNA methylation and gene expression, mechanisms that are also modulated by environmental factors (31). The study suggested hypomethylation in CREB5 gene in the decidual tissue was associated with RPL (58).

Next generation sequencing approaches further identified deleterious mutations that are likely causal. For example, by conducting whole exome sequencing (WES) using parental 
TABLE 1 | Studies that reported genetic factors associated with EPL.

\begin{tabular}{|c|c|c|c|c|c|c|c|c|}
\hline PMID & First author & Year & Pregnancy loss & Predictor(s) & Method & Sample size & Tissue(s) & Reference \\
\hline 16738225 & Liu & 2006 & Early Pregnancy Loss & $\begin{array}{l}\text { Alteration of protein } \\
\text { expression }\end{array}$ & Proteomic analysis & 12 & Placental chorionic villi & (18) \\
\hline 23433743 & Ventura & 2013 & Early Pregnancy Loss & $\begin{array}{l}\text { Placental Expression of } \\
\text { microRNA-17 } \\
\text { and-19b }\end{array}$ & $\begin{array}{l}\text { Matched case-control } \\
\text { expression microRNA } \\
\text { analysis using qPCR }\end{array}$ & 31 & Placental chorionic villi & (19) \\
\hline 24303885 & $\begin{array}{l}\text { Cöl- } \\
\text { Madendag }\end{array}$ & 2014 & Early Pregnancy Loss & $\begin{array}{l}\text { Vascular endothelial } \\
\text { growth factor (VEGF) } \\
\text { expression }\end{array}$ & $\mathrm{IHC}$ & 80 & $\begin{array}{l}\text { Placental chorionic villi; } \\
\text { endometrial decidua }\end{array}$ & (20) \\
\hline 26051097 & Fritz & 2015 & Early Pregnancy Loss & $\begin{array}{l}\text { Expression pattern of } \\
\text { biomarker proteins in } \\
\text { extravillous trophoblast } \\
(\text { EVT) cells }\end{array}$ & $\begin{array}{l}\text { Case-control study of } \\
\text { trophoblast retrieval } \\
\text { and isolation from the } \\
\text { cervix from ongoing } \\
\text { pregnancies }\end{array}$ & 20 & $\begin{array}{l}\text { Endocervical } \\
\text { specimens }\end{array}$ & $(21)$ \\
\hline 30074219 & Wu & 2018 & Early Pregnancy Loss & $\begin{array}{l}\text { TET family, 5-hmC } \\
\text { expression }\end{array}$ & $\begin{array}{l}\text { quantitative reverse } \\
\text { transcriptase } \\
\text { polymerase chain } \\
\text { reaction (qRT-PCR), } \\
\text { western blotting and } \\
\text { immunohistochemical } \\
(\mathrm{IHC}) \text { analyses }\end{array}$ & $>3$ & Placental chorionic villi & $(22)$ \\
\hline 29393376 & Hosseini & 2018 & Early Pregnancy Loss & $\begin{array}{l}\text { miRNAs (hsa-miRNA } \\
\text { (miR)-125a-3p, } \\
\text { hsa-miR-3663-3p, } \\
\text { hsa-miR-423-5p and } \\
\text { hsa-miR-575) }\end{array}$ & $\begin{array}{l}\text { miRNA expression } \\
\text { qRT-PCR analyses }\end{array}$ & 24 & $\begin{array}{c}\text { Maternal plasma; } \\
\text { placental chorionic villi }\end{array}$ & (23) \\
\hline 29165645 & Hong & 2018 & Early Pregnancy Loss & $\begin{array}{l}\text { miR-378a-3p } \\
\text { expression }\end{array}$ & $\begin{array}{l}\text { qRT-PCR, western } \\
\text { blotting, luciferase } \\
\text { reporter assays }\end{array}$ & 105 & Endometrial decidua & $(24)$ \\
\hline 31203134 & $\mathrm{He}$ & 2019 & Early Pregnancy Loss & $\begin{array}{l}\text { Serum- and } \\
\text { glucocorticoid- } \\
\text { inducible kinase (SGK1) } \\
\text { expression }\end{array}$ & $\begin{array}{l}\text { Gene expression } \\
\text { case-control analysis }\end{array}$ & 67 & Placental chorionic villi & $(16)$ \\
\hline 19389728 & Sarno & 2009 & Early Pregnancy Loss & HOX gene expression & $\begin{array}{l}\text { qRT-PCR and western } \\
\text { blotting analyses }\end{array}$ & 46 & Endometrial decidua & (25) \\
\hline
\end{tabular}

blood and placental chorionic villi samples, Qiao et al. (53) detected compound heterozygous deleterious mutations affecting DYNC2H1 and ALOX15 genes, both critical for early development, in two out of four families with RPL. Among unrelated women $(n=49)$ affected by RPL, Quintero-Ronderos et al. conducted WES in maternal leukocytes and detected 27 coding variants in 22 genes among $41 \%$ of the women. The affected genes, which were enriched by potentially deleterious sequence variants, belonged to distinct molecular cascades playing key roles in implantation (55). Furthermore, Shehab et al. conducted WGS analyses using maternal blood, unaffected offspring blood and fetal tissue in families $(n=7)$ with recurrent fetal death and detected a frameshift mutation in FOXP3 gene. The authors confirmed the mutation in the affected fetal tissue using Sanger sequencing.

\section{Genetic Factors Associated With Unclassified Pregnancy Loss}

Three studies were based on unclassified pregnancy loss, assessed over a broad range of gestational ages (Table 4). CocheryNouvellon et al. conducted a candidate gene study using 3,218 case (experienced embryonic loss at $<10$ weeks and fetal loss $\geq 10$ weeks gestation) and 6,436 control motherfather pairs, the largest 1:2 matched case-control family-based study included in our review (66). The authors reported that the A6936G allele of PROCR, an endothelial protein C receptor gene involved in coagulation (Table 5), in maternal and paternal blood is associated with fetal death. The authors confirmed the association between candidate gene Factor $\mathrm{V}$ Leiden (F5), also involved in coagulation, and fetal loss, but pointed out that relationship between thrombophilias and pregnancy loss varies according to ethnicity and loss type. Alonso et al. (64) also examined mutations in the F5 gene in first-trimester abortions (at $\leq 12$ weeks of gestation), secondtrimester abortions (at $13-22$ weeks of gestation), and fetal death (at $\geq 23$ weeks) of mothers $(n=75)$. The presence of thrombophilia in $75 \%$ of the women combined with a mutation in F5 gene was marginally associated with intrauterine fetal death $(P=0.04$; OR $=12$; 95\%CI: $1.44-102)$.

\section{Genetic/Multi-Omic Pathways of Pregnancy Loss}

Among the 54 studies included in this review, 26 (48\%) examined placental tissue (e.g., chorionic villous tissue and 
TABLE 2 | Studies that reported genetic factors associated with losses > 20 weeks' gestation.

\begin{tabular}{|c|c|c|c|c|c|c|c|c|}
\hline PMID & First author & Year & Pregnancy loss & Predictor(s) & Method & Sample size & Tissue(s) & Reference \\
\hline 15963226 & Wicherek & 2005 & $\begin{array}{l}\text { Loss } \geq 24 \text { weeks' } \\
\text { gestation }\end{array}$ & $\begin{array}{l}\text { Placental RCAS1 } \\
\text { expression }\end{array}$ & $\begin{array}{l}\text { Western blot method } \\
\text { with the use of } \\
\text { monoclonal } \\
\text { anti-RCAS1 antibody }\end{array}$ & 67 & Placental & (26) \\
\hline 21732394 & Harris & 2011 & $\begin{array}{l}\text { Loss }>22 \text { weeks' } \\
\text { gestation }\end{array}$ & $\begin{array}{l}\text { Genomic structural } \\
\text { variations; CNVs }\end{array}$ & $\begin{array}{l}\text { Genome-wide analysis } \\
\text { using high-resolution } \\
\text { Illumina SNP arrays } \\
\text { (Human CNV370-Duo) }\end{array}$ & 54 & $\begin{array}{c}\text { Placental tissue; fetal } \\
\text { tissue }\end{array}$ & $(27)$ \\
\hline 23021696 & Ferrari & 2012 & $\begin{array}{l}\text { Loss }>22 \text { weeks' } \\
\text { gestation }\end{array}$ & $\begin{array}{l}\text { SNPs in endothelial } \\
\text { nitric oxide synthase } \\
\text { (eNOS) gene }\end{array}$ & $\begin{array}{l}\text { Case-control candidate } \\
\text { SNP association }\end{array}$ & 96 & Placental tissue & $(28)$ \\
\hline 23215556 & Reddy & 2012 & $\begin{array}{l}\text { Loss } \geq 20 \text { weeks' } \\
\text { gestation }\end{array}$ & CNVs of at least $500 \mathrm{~kb}$ & $\begin{array}{l}\text { Chromosomal } \\
\text { microarray analysis } \\
\text { (case-only) }\end{array}$ & 532 & $\begin{array}{c}\text { Placental tissue; fetal } \\
\text { tissue }\end{array}$ & (3) \\
\hline 26094028 & Ernst & 2015 & $\begin{array}{l}\text { Loss } \geq 23 \text { weeks' } \\
\text { gestation }\end{array}$ & $\begin{array}{l}\text { Fetal copy-number } \\
\text { variation (CNV) }\end{array}$ & $\begin{array}{l}\text { Retrospective } \\
\text { case-control microarray } \\
\text { and qPCR analyses }\end{array}$ & 94 & Umbilical cord & (29) \\
\hline 27131585 & Silver & 2016 & $\begin{array}{l}\text { Loss } \geq 20 \text { weeks' } \\
\text { gestation }\end{array}$ & $\begin{array}{l}\text { Maternal factor } V \\
\text { Leiden; fetal PAI-1 } \\
\text { 4G/4G polymorphism }\end{array}$ & $\begin{array}{l}\text { Case-control candidate } \\
\text { single nucleotide } \\
\text { polymorphism (SNP) } \\
\text { association }\end{array}$ & 1,830 & $\begin{array}{c}\text { Maternal serum; fetal } \\
\text { cord blood; placental } \\
\text { chorionic villi }\end{array}$ & $(30)$ \\
\hline 26827667 & Romagnuolo & 2016 & $\begin{array}{l}\text { Loss }>24 \text { weeks' } \\
\text { gestation }\end{array}$ & $\begin{array}{l}\text { Lp(a) levels } \\
\text { measurement }\end{array}$ & $\begin{array}{l}\text { Retrospective } \\
\text { observational study }\end{array}$ & 630 & $\begin{array}{c}\text { Maternal blood } \\
\text { leukocytes; maternal } \\
\text { blood }\end{array}$ & (31) \\
\hline 26004986 & Ferrari & 2016 & $\begin{array}{l}\text { Loss }>22 \text { weeks' } \\
\text { gestation }\end{array}$ & $\begin{array}{l}\text { Placental telomere } \\
\text { shortening }\end{array}$ & $\begin{array}{l}\text { qPCR of } 42 \\
\text { unexplained stillbirths } \\
\text { (>22 weeks), } 43 \text { term } \\
\text { and } 15 \text { preterm live } \\
\text { births }\end{array}$ & 100 & Placental tissue & \\
\hline 28645573 & Maiti & 2017 & $\begin{array}{l}\text { Loss } \geq 32 \text { weeks' } \\
\text { gestation }\end{array}$ & $\begin{array}{l}\text { Aldehyde oxidase } 1 \\
\text { and G-protein-coupled } \\
\text { estrogen receptor } 1\end{array}$ & $\begin{array}{l}\mathrm{IHC} \text { and gene } \\
\text { expression analyses } \\
\text { using qRT-PCR }\end{array}$ & 4 & Placental chorionic villi & (32) \\
\hline 28990860 & Campbell & 2018 & $\begin{array}{l}\text { Loss } \geq 24 \text { weeks' } \\
\text { gestation }\end{array}$ & $\begin{array}{l}\text { Genetic test results, } \\
\text { placental pathology }\end{array}$ & $\begin{array}{l}\text { Review of pathology } \\
\text { reports and collected } \\
\text { demographic data on } \\
\text { cases }\end{array}$ & 131 & Placental & (33) \\
\hline
\end{tabular}

trophoblast cells) and reported placental genetic factors associated with pregnancy loss across the developmental epochs. Two studies (4\%) incorporated samples from parent-offspring trios (maternal, paternal and fetal/placental) and identified genetic factors related to recurrent losses. Twenty-three studies (53\%) examined genetic factors assessed in the maternal tissue samples only (Figure 2). Multiple genetic pathways associated with embryonic and fetal survival may play a role in pregnancy loss. The reported pathways are essential for placental function, epigenetic reprogramming, embryonic development and several critical cellular functions (Table 5).

\section{DISCUSSION}

In this review we identified 54 research studies that reported genetic/multi-omic etiologies underlying pregnancy loss. Twenty-six studies examined DNA from placental and/or fetal tissues, including two studies with maternal and paternal samples, and supported their findings on genetic abnormalities associated with pregnancy loss. Based on data from studies included in this review, multiple genes with functional pathways that may be essential for embryonic/fetal survival were discussed.

\section{Genetic Factors Associated With Pregnancy Loss}

Eight studies reported genetic/multi-omic etiologies of EPL, however, the studies examined miRNAs, including other epigenetic regulators and proteins that require utilization of expensive targeted assays (e.g., qRT-PCR and immunohistochemistry). Epigenetic mechanisms may play an important role in placental development and function, but are also modulated by environmental factors (7). Indeed, the etiology of many pregnancy losses could be multifactorial, including genetic and environmental factors; however, in some couples, pregnancy loss can be inherited as a Mendelian trait (i.e., monogenic form) (67). Despite the strong genetic underpinnings underlying EPL $(10,68)$, evidence for causal genetic variants is lacking. 
TABLE 3 | Studies that reported genetic factors associated with RPL.

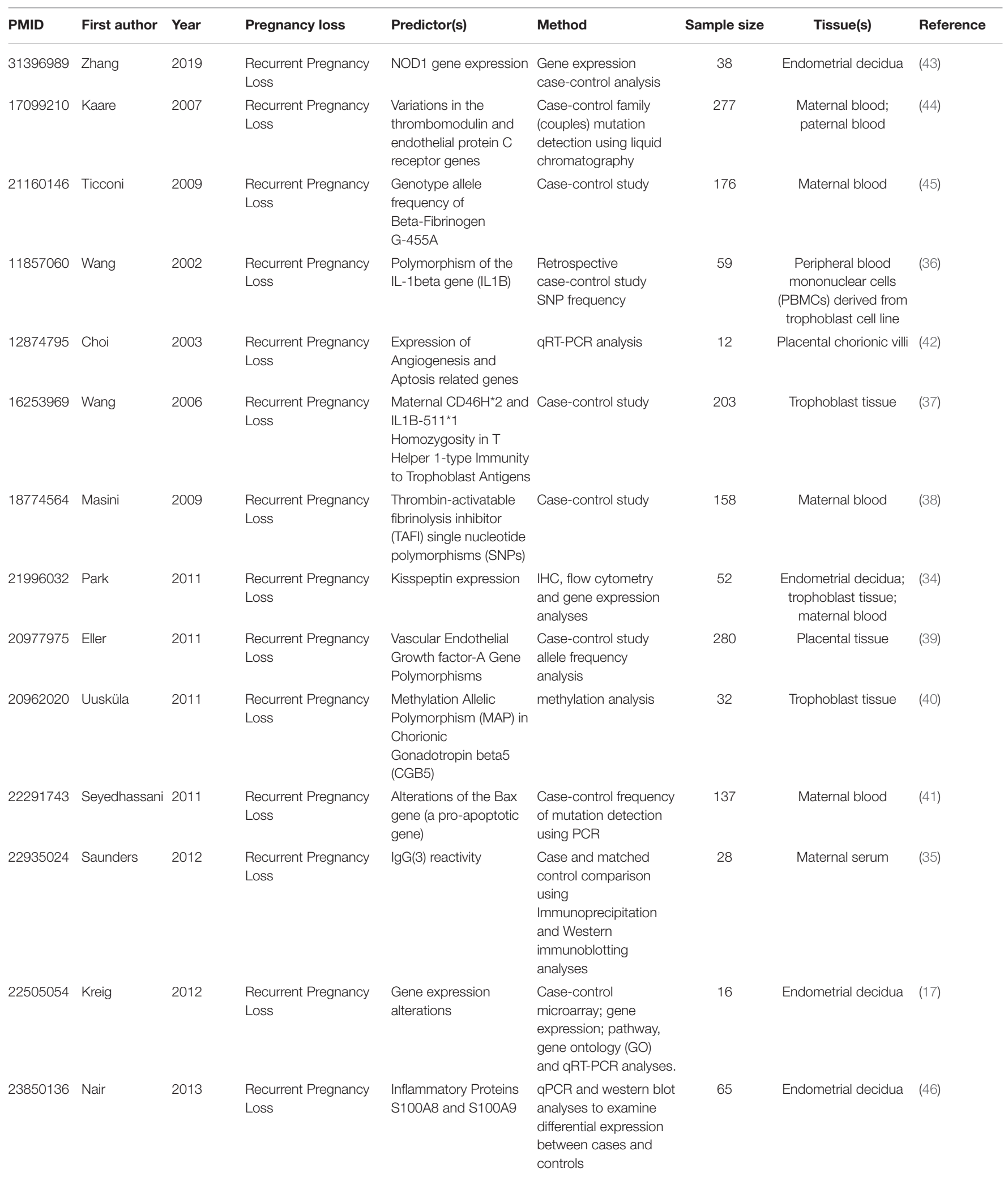


TABLE 3 | Continued

\begin{tabular}{|c|c|c|c|c|c|c|c|c|}
\hline PMID & First author & Year & Pregnancy loss & Predictor(s) & Method & Sample size & Tissue(s) & Reference \\
\hline 23498654 & Rogenhofer & 2013 & $\begin{array}{l}\text { Recurrent Pregnancy } \\
\text { Loss }\end{array}$ & $\begin{array}{l}\text { M2 haplotype of } \\
\text { ANXA5 gene }\end{array}$ & $\begin{array}{l}\text { Comparing M2/ANXA5 } \\
\text { genotype among } 100 \\
\text { PCOS, } 500 \text { fertile and } \\
533 \text { random population } \\
\text { control women }\end{array}$ & 1,133 & Maternal blood & $(47)$ \\
\hline 25956264 & $\mathrm{Jin}$ & 2015 & $\begin{array}{l}\text { Recurrent Pregnancy } \\
\text { Loss }\end{array}$ & $\begin{array}{l}\text { HMGB1 } \\
\text { rs2249825C/G and } \\
\text { rs1412125T/C } \\
\text { polymorphisms }\end{array}$ & $\begin{array}{l}\text { Case-control study of } \\
\text { PCR-restriction } \\
\text { fragment length } \\
\text { polymorphism assay } \\
\text { analyses }\end{array}$ & 230 & Placental chorionic villi & (48) \\
\hline 25925347 & Perfetto & 2015 & $\begin{array}{l}\text { Recurrent pregnancy } \\
\text { Loss }\end{array}$ & IL-22 levels & $\begin{array}{l}\text { qPCR, Western blot, } \\
\text { and IHC }\end{array}$ & 20 & Endometrial decidua & (49) \\
\hline 27535546 & $\mathrm{He}$ & 2016 & $\begin{array}{l}\text { Recurrent Pregnancy } \\
\text { Loss }\end{array}$ & $\begin{array}{l}\text { Early pregnancy } \mathrm{Cx} 43 \\
\text { and VEGF mRNA and } \\
\text { protein expression }\end{array}$ & $\begin{array}{l}\text { IHC, western blot, and } \\
\text { qRT-PCR analyses }\end{array}$ & 56 & $\begin{array}{l}\text { Placental chorionic villi; } \\
\text { endometrial decidua }\end{array}$ & (50) \\
\hline 27929073 & Sober & 2016 & $\begin{array}{l}\text { Recurrent Pregnancy } \\
\text { Loss }\end{array}$ & $\begin{array}{l}\text { Gene expression } \\
\text { alterations }\end{array}$ & $\begin{array}{l}\text { Case-control RNA } \\
\text { differential sequencing } \\
\text { (DESeq) analysis }\end{array}$ & 10 & Placental chorionic villi & (52) \\
\hline 26826164 & Qiao & 2016 & $\begin{array}{l}\text { Recurrent Pregnancy } \\
\text { Loss }\end{array}$ & $\begin{array}{l}\text { DNA alterations within } \\
\text { exons }\end{array}$ & Case-only family WES & 4 & $\begin{array}{l}\text { Maternal blood; } \\
\text { paternal blood; } \\
\text { placental chorionic villi }\end{array}$ & (53) \\
\hline 28345611 & Kasak & 2017 & $\begin{array}{l}\text { Recurrent Pregnancy } \\
\text { Loss }\end{array}$ & $\begin{array}{l}\text { NUP98 (embryonic } \\
\text { stem cell development) } \\
\text { and MTRR (folate } \\
\text { metabolism) genes }\end{array}$ & $\begin{array}{l}\text { Copy number variant } \\
\text { (CNV) analysis of } \\
\text { idiopathic RPL trios } \\
\text { (mother-father- } \\
\text { placenta) and duos } \\
\text { (mother-placenta) }\end{array}$ & 79 & $\begin{array}{l}\text { Maternal blood; } \\
\text { paternal blood; } \\
\text { placental chorionic villi }\end{array}$ & (7) \\
\hline 28833278 & Shehab & 2017 & $\begin{array}{l}\text { Recurrent Pregnancy } \\
\text { Loss }\end{array}$ & $\begin{array}{l}\text { FOXP3 gene frameshift } \\
\text { mutations } \\
(\text { p.D303fs*87) }\end{array}$ & $\begin{array}{l}\text { Whole genome } \\
\text { sequencing of families }\end{array}$ & 7 & $\begin{array}{l}\text { Maternal blood; } \\
\text { unaffected offspring } \\
\text { blood; fetal tissue }\end{array}$ & (56) \\
\hline 30348621 & $\mathrm{Li}$ & 2018 & $\begin{array}{l}\text { Recurrent Pregnancy } \\
\text { Loss }\end{array}$ & $\begin{array}{l}\text { ITI-H4 and plasma } \\
\text { kallikrein (KLKB1) }\end{array}$ & $\begin{array}{l}\text { Gene expression } \\
\text { case-control analysis }\end{array}$ & 90 & $\begin{array}{l}\text { Maternal serum; } \\
\text { maternal blood }\end{array}$ & (57) \\
\hline 30100398 & Yu & 2018 & $\begin{array}{l}\text { Recurrent Pregnancy } \\
\text { Loss }\end{array}$ & CREB5 expression & $\begin{array}{l}\text { Genome-wide DNA } \\
\text { methylation and gene } \\
\text { expression analyses }\end{array}$ & 100 & Endometrial decidua & (58) \\
\hline 24557735 & Papamitsou & 2014 & $\begin{array}{l}\text { Recurrent Pregnancy } \\
\text { Loss }\end{array}$ & $\begin{array}{l}\text { Expressions of HLAG } \\
\text { (Human Leukocyte } \\
\text { Antigen G), CD68 } \\
\text { (Cluster of } \\
\text { Differentiation 68), } \\
\text { CD56, CD16 and CD25 } \\
\text { during pregnancy }\end{array}$ & $\mathrm{HC}$ & 50 & Endometrial decidua & (59) \\
\hline 11279300 & Pfeiffer & 2001 & $\begin{array}{l}\text { Recurrent Pregnancy } \\
\text { Loss }\end{array}$ & $\begin{array}{l}\text { Human leukocyte } \\
\text { antigen }(H\llcorner A)-G \\
\text { genotype }\end{array}$ & $\begin{array}{l}\text { Case-control } \\
\text { comparison of } \\
\text { haplotypes }\end{array}$ & 130 & $\begin{array}{l}\text { Maternal blood; } \\
\text { paternal blood }\end{array}$ & (60) \\
\hline
\end{tabular}


TABLE 3 | Continued

\begin{tabular}{|c|c|c|c|c|c|c|c|c|}
\hline PMID & First author & Year & Pregnancy loss & Predictor(s) & Method & Sample size & Tissue(s) & Reference \\
\hline 16403802 & Kaare & 2006 & $\begin{array}{l}\text { Recurrent Pregnancy } \\
\text { Loss }\end{array}$ & $\begin{array}{l}\text { Homozygous } \\
\text { mutations in the } \\
\text { Amnionless (AMN) } \\
\text { gene }\end{array}$ & $\begin{array}{l}\text { Case-only Families } \\
\text { (couples) sequence } \\
\text { variation detection } \\
\text { using liquid } \\
\text { chromatography }\end{array}$ & 85 & $\begin{array}{l}\text { Maternal blood; } \\
\text { paternal blood }\end{array}$ & (61) \\
\hline 25457193 & Agrawal & 2015 & $\begin{array}{l}\text { Recurrent Pregnancy } \\
\text { Loss }\end{array}$ & $\begin{array}{l}\text { HLA-G } 5 \text { ' upstream } \\
\text { regulatory region SNPs }\end{array}$ & $\begin{array}{l}\text { Case-control } \\
\text { comparison of } \\
\text { haplotypes }\end{array}$ & 200 & $\begin{array}{l}\text { Maternal blood; } \\
\text { paternal blood }\end{array}$ & (62) \\
\hline 24621454 & Gharesi-Fard & 2014 & $\begin{array}{l}\text { Recurrent Pregnancy } \\
\text { Loss }\end{array}$ & $\begin{array}{l}\text { Proteins involved in } \\
\text { proliferation and } \\
\text { migration of endothelial } \\
\text { cells as well as control } \\
\text { of coagulation }\end{array}$ & $\begin{array}{l}\text { Differential expression } \\
\text { analysis using qPCR } \\
\text { and Western blot } \\
\text { techniques }\end{array}$ & 10 & Placental tissue & (63) \\
\hline
\end{tabular}

TABLE 4 | Studies that reported genetic factors associated with unclassified pregnancy loss.

\begin{tabular}{|c|c|c|c|c|c|c|c|c|}
\hline PMID & First author & Year & Pregnancy loss & Predictor(s) & Method & Sample size & Tissue(s) & Reference \\
\hline 12439528 & Alonso & 2002 & $\begin{array}{l}\text { Unclassified Pregnancy } \\
\text { Loss }\end{array}$ & $\begin{array}{l}\text { Mutations of factor } V \\
\text { Leiden, } \\
\text { methylenetetrahydrofolate } \\
\text { reductase, and } \\
\text { prothrombin gene }\end{array}$ & $\begin{array}{l}\text { Case-control ELISA } \\
\text { analysis }\end{array}$ & 150 & Maternal blood & (64) \\
\hline 30136429 & Mehandjiev & 2018 & $\begin{array}{l}\text { Unclassified Pregnancy } \\
\text { Loss }\end{array}$ & $\begin{array}{l}\text { MTHFR C677T TT } \\
\text { genotype and T allele }\end{array}$ & Cross-sectional study & 243 & Endometrial decidua & $(65)$ \\
\hline 19806250 & $\begin{array}{l}\text { Cochery- } \\
\text { Nouvellon }\end{array}$ & 2009 & $\begin{array}{l}\text { Unclassified Pregnancy } \\
\text { Loss }\end{array}$ & $\begin{array}{l}\text { A6936G allele of the } \\
\text { endothelial protein C } \\
\text { receptor (EPCR) gene } \\
\text { (PROCR) }\end{array}$ & $1: 2$ case-control study & 9,654 & $\begin{array}{l}\text { Maternal blood; } \\
\text { paternal blood }\end{array}$ & (66) \\
\hline
\end{tabular}

Among genome-wide association studies of pregnancy loss at 20 weeks' gestation or more, two studies utilized chromosomal microarray, a higher resolution and enhanced sensitivity method that allowed unbiased detection of pathogenic abnormalities $(3,27)$. These studies by Reddy et al and Harris et al detected 24 putative novel CNVs in 54 placental and fetal samples from losses $>20$ and 22 weeks' gestation, respectively, and genetic abnormalities explained $41.9 \%$ of idiopathic cases $(3,27)$. A recent study, that was not included in our review due to its publication date, improved these findings by utilizing NGS approach that allowed detection of the de novo lethal mutations and the "intolerome" (i.e., genes that are critical for human development, the loss of which is incompatible with life) (11). Using the maternal and fetal samples, enrichment of loss-offunction variants in genes that are intolerant to variation in the human population were observed. This suggested dramatic and progressive increases in the proportion of losses $>20$ weeks' gestation with likely causative genetic abnormalities, however, the genetic etiologies of $40 \%$ of idiopathic cases remain to be elucidated. Due to unavailability of paternal samples in the previous studies, they could not detect compound heterozygous variants, distinguish pathogenic de novo from inherited variants and consequently could not explain significant proportion of idiopathic cases. Additional efforts were made by CocheryNouvellon et al. (66) that utilized mother-father duos with larger sample size. However, the study was a candidate gene study and showed limited evidence of association between coagulation pathway genes and unclassified pregnancy loss.

Among thirty-two studies that reported genetic etiologies of RPL, making up the majority of studies included in this review, two utilized an NGS approach in families to identify deleterious mutations that are likely causal $(53,56)$. Using WES analysis in parental blood and placental chorionic villi samples, Qiao et al. (53) detected compound heterozygous deleterious mutations affecting DYNC2H1 and ALOX15, genes critical for early development, in two out of four families with RPL. By conducting WGS followed by Sanger sequencing validation analyses, Shehab et al. (56) detected frameshift mutation in FOXP3 gene that is critical for the function of regulatory $\mathrm{T}$ cells in families affected by recurrent intrauterine fetal death. Other genes such as loss-of-function risk variants and inherited pathogenic mutations in intolerant genes were not identified, potentially due to the lack of larger parent-offspring trio studies.

\section{Guide to Next Steps in Determining Genetic Factors Associated With Pregnancy Loss}

While chromosomal microarray, the current clinical guideline for genetic evaluation of losses $>20$ weeks' gestation, enhanced 
TABLE 5 | Reported genetic/multi-omic pathways in relation to gestational age specific pregnancy.

\begin{tabular}{|c|c|c|c|}
\hline Pregnancy loss phenotype & $\begin{array}{l}\text { Genes, microRNAs, mRNAs, or } \\
\text { chromosomes }\end{array}$ & Functional pathway & Number of studies \\
\hline \multirow[t]{8}{*}{ Early pregnancy loss } & & & 7 \\
\hline & $\begin{array}{l}\text { SGK1, miR-575, miRNA-17, miRNA-19b, } \\
\text { VEGF }\end{array}$ & Placental function & \\
\hline & TET family, 5-hmC & Epigenetic reprogramming & \\
\hline & miR-125a, miR-3663-3p & Mitosis, meiosis, cell cycle progression & \\
\hline & $\begin{array}{l}\text { miR-3663-3p, miR-135a, miR-122, let-7, } \\
\text { miR-378a-3p }\end{array}$ & Apoptosis & \\
\hline & $\operatorname{miR}-125 a$ & Hematopoiesis & \\
\hline & miR-125a, miR-135a & Implantation & \\
\hline & HOX family & Endometrial function & \\
\hline \multirow[t]{7}{*}{ Losses $\geq 20$ weeks' gestation } & & & 6 \\
\hline & F5, PAl-1, eNOS & Coagulation & \\
\hline & AOX-1, GPER & Oxidation and cellular aging & \\
\hline & LPA & Lipoprotein synthesis & \\
\hline & Ch 1q31.3, NOS3, RCAS1 & Inflammation and immunity & \\
\hline & eNOS & Mitosis, meiosis, cell cycle progression & \\
\hline & eNOS & Vascular tone & \\
\hline \multirow[t]{14}{*}{ Recurrent pregnancy loss } & & & 32 \\
\hline & $\begin{array}{l}\text { NOD1, ITI-H4, KLKB1, IL-22, HLAG, CD16, } \\
\text { CD68, CD56, S100A8, S100A9, KISS1, IL1B, } \\
\text { CD46, FOXP3, NLRP2, NLRP5, NLRP7, IDO2 }\end{array}$ & Inflammation and immunity & \\
\hline & CREB5, DYNC2H1, PLCD4, OSBPL5, STIL & Mitosis, meiosis, cell cycle progression & \\
\hline & CREB5, BAX, CASP9 & Apoptosis & \\
\hline & $\begin{array}{l}\text { NUP98, IFT122, APAF1, CASP9, CSPP1, } \\
\text { NLRP5, PADI6 }\end{array}$ & Embryonic development & \\
\hline & MTRR, VDR & Folate and other vitamin metabolism & \\
\hline & Cx43, VEGF, ALOX15 & Placental function & \\
\hline & Cx43, VEGF, VEGFA, FLT1, EPAS1 & Angiogenesis & \\
\hline & ANXA5, TAFI, THBD, FGA, FGB, PROCR & Coagulation & \\
\hline & KISS1, CHRNA1, RYR1, MUSK & Cell signaling & \\
\hline & CGB5 & Implantation & \\
\hline & KIF14, IFT122, DYNC2H1 & Ciliogenesis & \\
\hline & MMP10 & Extracellular matrix organization & \\
\hline & CAPS & Ion transport & \\
\hline \multirow[t]{3}{*}{ Unclassified fetal death } & & & 3 \\
\hline & PROCR, F5, F2 & Coagulation & \\
\hline & MTHFR & Folate and other vitamin metabolism & \\
\hline
\end{tabular}

the ability to detect microdeletions and duplications beyond the resolution of standard karyotype, additional detailed diagnostic yields will require utilization of NGS approach. Efforts are underway to apply this technology to losses $>20$ weeks' gestation (69).

With the advent of NGS, monogenic disorders (including de novo, inherited autosomal-dominant/autosomal-recessive mutations, and SNPs) that are either lethal, known to cause disease, or dramatically increase risk of pregnancy loss in families can be identified. De novo mutations occur as likely penetrant variation in a Mendelian gene and could explain sporadic cases of pregnancy loss. Point mutations, other genetic variations such as CNVs (genomic deletions or duplications), as identified by studies in this review, may also occur de novo. The added contribution of novel de novo missense variants to losses $>20$ weeks' gestation was estimated by pulling all rare and damaging novel missense variants in the study (11). Therefore, the authors estimated a bound on the diagnostic yield in known genes associated with losses $>20$ weeks' gestation between the previously reported yield (4.5\%) vs. the present yield (13.4\%; 36/268 cases). However, without parental genotype information, the study remained at the lower bound of the diagnostic yield. Consistent with other diagnostic studies, the diagnostic yield using parent-offspring trios is estimated to be up to three-fold higher compared with studies that use singletons (70). 


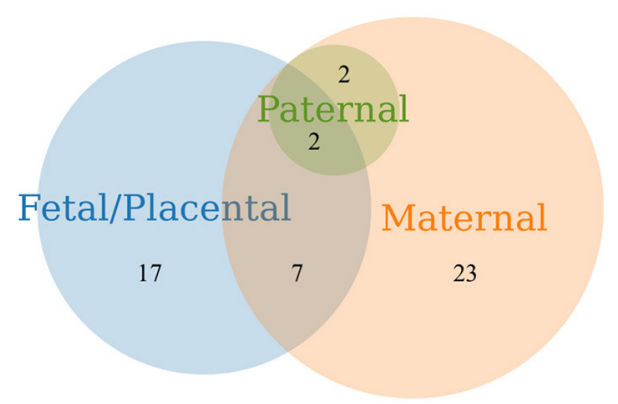

FIGURE 2 | Venn diagram of pregnancy loss studies that examined genetic factors assessed in products of conception obtained from fetal/placental and parental samples.

Combined with identification of de novo mutations, other single gene abnormalities may be used to provide prognosis based on data from other patients with similar mutations (71). Such monogenic forms may be associated with extreme phenotypes and early losses, but this is not always the case. Studies that show familial aggregation of pregnancy loss may help clarify whether losses that occur early in gestation and a positive family history exists, suggesting autosomal-dominant transmission of risk alleles. To prove whether the mutations appeared in the germline of the probands as de novo mutations, parental DNA assessment is required (67).

Challenges still remain in clinical applications of genome sequencing and validating the results from sequencing using maternal cell-free DNA, chorionic villus sampling and amniocentesis. Suggested strategies to overcome these challenges include serial assessment of genotypes, phenotypes and 'omics data over the course of the pregnancy (e.g., genomics, transcriptomics, metabolomics) $(10,68)$. Molecular diagnostic evaluations rely on databases (e.g., OMIM) and guidelines of the American College of Medical Genetics and Genomics with characteristics designed to enrich for pathogenicity in Mendelian disease genes (11). In these databases, lethal phenotypes are especially poorly represented. Other strategies for gene discovery, including determination of the "intolerome" are likely to reveal new genotype-phenotype correlations and shed light on the human "intolerome," conditions incompatible with life resulting in fetal demise $(11,13)$. Studies that incorporate DNA sequencing in affected and unaffected families, designed as case-control trio studies, will help in determination of the "intolerome" by identifying novel embryonic-lethal or fetal-lethal variants that are not seen in unaffected families. Using WGS in parent-offspring trios, 60-80 high confidence de novo mutations per individual can be identified (67). Compared with WES, WGS may further expand the spectrum of causal de novo mutations by allowing for a better coverage of the exome and identification of non-coding variants.

\section{Limitations and Strengths of the Systematic Review}

Although PubMed search is a comprehensive retrieval tool appropriate for systematic review of journal research in health care, other search methods (e.g., Embase, Web of Science) were not utilized. Restricted MeSH terms applied in PubMed may have excluded other studies pertinent to the present systematic review. To provide a more comprehensive review of the literature, we reviewed and included studies within review articles that matched eligibility in our search criteria. In addition, we independently explored OMIM to report and confirm genetic pathways and functional effects of the reported genes.

\section{Guide to Next Steps}

Experts have recommended categorization of pregnancy loss as: $<10$ weeks gestational age (termed early pregnancy loss), 1019 weeks and 6 days of gestation (termed fetal death), and 20 or more weeks gestation (termed stillbirth). EPL was further subdivided into peri-implantational loss before 5 weeks, preembryonic loss from 5 to 5 weeks and 6 days of gestation, and embryonic loss from 6 to 9 weeks and 6 days of gestation (14). Similarly, fetal death can be subdivided into early fetal death, defined as losses between 10 and 15 weeks and 6 days of gestation, and late fetal death, losses from 16 to 19 weeks and 6 days of gestation (14). These classifications may identify studies that report genetic factors with different mechanisms, e.g., genes essential for embryonic lethality and functional genes essential for human development (e.g., cardiomyopathy). Additionally, assessment of losses at different stages of pregnancy may help identify pathways essential for in utero survival at critical stages of development.

\section{CONCLUSION}

Pregnancy loss is multi-factorial, but recent studies identified genetic pathways essential for embryonic and fetal survival. Further research systematically evaluating pregnancy loss across various developmental epochs and utilizing NGS in families may identify single-gene mutations causing embryonic/fetal loss and that are not found in healthy controls. Identification of such genes and their pathways may provide novel biomarkers for risk stratification and therapeutic targets to improve pregnancy outcomes.

\section{DATA AVAILABILITY STATEMENT}

The original contributions presented in the study are included in the article/supplementary material, further inquiries can be directed to the corresponding author.

\section{AUTHOR CONTRIBUTIONS}

The literature search was conducted and cross-examined by AC and TW. AC, NB, MV, TW, and RS directed its implementation. AC and TW drafted the manuscript. All authors reviewed the article and revised it critically for important intellectual content, and all authors provided final approval of the draft being submitted. 


\section{FUNDING}

Research reported in this publication was supported in part by the National Center for Advancing Translational

\section{REFERENCES}

1. Feodor Nilsson S, Andersen PK, Strandberg-Larsen K, Nybo Andersen A-M. Risk factors for miscarriage from a prevention perspective: a nationwide follow-up study. BJOG : Int J Obstetrics Gynaecol. (2014) 121:94. doi: 10.1111/1471-0528.12694

2. Rossen LM, Ahrens KA, Branum AM. Trends in risk of pregnancy loss among us women, 1990-2011. Paediatric Perinat Epidemiol. (2018) 32:1929. doi: 10.1111/ppe.12417

3. Reddy UM, Page GP, Saade GR, Silver RM, Thorsten VR, Parker CB, et al. Karyotype versus microarray testing for genetic abnormalities after stillbirth. N E J Med.. (2012) 367:2185-93. doi: 10.1056/NEJMoa1201569

4. Frias AE, Luikenaar RA, Sullivan AE, Lee RM, Porter TF, Branch DW, et al. Poor obstetric outcome in subsequent pregnancies in women with prior fetal death. Obstet Gynecol. (2004) 104:5216. doi: 10.1097/01.AOG.0000137350.89939.2a

5. No RGG. The Investigation and Treatment of Couples With Recurrent Firsttrimester and Second-trimester Miscarriage. RCOG: London (2011).

6. Warren JE, Silver RM. Genetics of pregnancy loss. Clinic Obstetric Gynecol. (2008) 51:84-95. doi: 10.1097/GRF.0b013e318161719c

7. Kasak L, Rull K, Sõber S, Laan M. Copy number variation profile in the placental and parental genomes of recurrent pregnancy loss families. Sci Rep. (2017) 7:45327. doi: 10.1038/srep45327

8. Branch DW, Heuser C. "Recurrent Miscarriage," In: Carrell CM, Peterson DT, editors. Reproductive Endocrinology Infertility: Integrating Modern Clinical Laboratory Practice (New York, NY: Springer), 281-296.

9. Wilson RD, Gagnon A, Audibert F, Campagnolo C, Carroll J, Wilson RD, et al. Prenatal diagnosis procedures and techniques to obtain a diagnostic fetal specimen or tissue: maternal and fetal risks and benefits. J Obstetric Gynaecol Canada. (2015) 37:656-668. doi: 10.1016/S1701-2163(15)30205-X

10. Blue NR, Page JM, Silver RM. Genetic abnormalities and pregnancy loss. Semin Perinatol. (2019) 43:66-73. doi: 10.1053/j.semperi.2018.12.002

11. Stanley KE, Giordano J, Thorsten V, Buchovecky C, Thomas A, Ganapathi $\mathrm{M}$, et al. Causal genetic variants in stillbirth. NE J Med. (2020) 383:110716. doi: 10.1056/NEJMoa1908753

12. Pereza N, Ostojić S, Kapović M, Peterlin B. Systematic review and metaanalysis of genetic association studies in idiopathic recurrent spontaneous abortion. Fertil Steril. (2017) 107:150-9. doi: 10.1016/j.fertnstert.2016.10.007

13. Gray KJ, Wilkins-Haug L. Special issue on "Feto-Maternal Genomic Medicine": a decade of incredible advances. Hum Genet. (2020) 139:111920. doi: 10.1007/s00439-020-02217-4

14. Silver RM, Branch DW, Goldenberg R, Iams JD, Klebanoff MA. nomenclature for pregnancy outcomes: time for a change. Obstetric Gynecol. (2011) 118:1402-8. doi: 10.1097/AOG.0b013e3182392977

15. Robbins SM, Thimm MA, Valle D, Jelin AC. Genetic diagnosis in first or second trimester pregnancy loss using exome sequencing: a systematic review of human essential genes. $J$ Assist Reprod Genet. (2019) 36:1539-48. doi: 10.1007/s10815-019-0 1499-6

16. He W-H, Jin M-M, Liu A-P, Zhou Y, Hu X-L, Zhu Y-M, et al. Estradiol promotes trophoblast viability and invasion by activating SGK1. Biomed Pharmacother. (2019) 117:109092. doi: 10.1016/j.biopha.2019.1 09092

17. Krieg SA, Fan X, Hong Y, Sang Q-X, Giaccia A, Westphal LM, et al. Global alteration in gene expression profiles of deciduas from women with idiopathic recurrent pregnancy loss. Mol Hum Reprod. (2012) 18:44250. doi: 10.1093/molehr/gas017

18. Liu AX, Jin F, Zhang WW, Zhou TH, Zhou CY, Yao WM, et al. Proteomic analysis on the alteration of protein expression in the placental
Sciences of the National Institutes of Health under Award Number 1UL01TR002538. This funding as well as funding from the University of Utah support open access publication fees. villous tissue of early pregnancy loss. Biol Reprod. (2006) 75:414-20. doi: 10.1095/biolreprod.105.049379

19. Ventura W, Koide K, Hori K, Yotsumoto J, Sekizawa A, Saito H, et al. Placental expression of microRNA-17 and $-19 \mathrm{~b}$ is down-regulated in early pregnancy loss. Eur J Obstet Gynecol Reprod Biol. (2013) 169:28-32. doi: 10.1016/j.ejogrb.2013.01.0245

20. Cöl-Madendag I, Madendag Y, Altinkaya SÖ, Bayramoglu H, Danisman N. The role of VEGF and its receptors in the etiology of early pregnancy loss. Gynecol Endocrinol. (2014) 30:153-6. doi: 10.3109/09513590.2013.864272

21. Fritz R, Kohan-Ghadr H-R, Bolnick JM, Bolnick AD, Kilburn BA, Diamond MP, et al. Noninvasive detection of trophoblast protein signatures linked to early pregnancy loss using TRIC. Fertil Steril. (2015) 104:33946. doi: 10.1016/j.fertnstert.2015.05.010

22. Wu AH, Yang DY, Liu YD, Chen X, Chen XL, Lu S, et al. Expression of TET and 5-HmC in trophoblast villi of women with normal pregnancy and with early pregnancy loss. Curr Med Sci. (2018) 38:505-12. doi: 10.1007/s11596-018-1907-0

23. Hosseini MK, Gunel T, Gumusoglu E, Benian A, Aydinli K. MicroRNA expression profiling in placenta and maternal plasma in early pregnancy loss. Mol Med Rep. (2018) 17:4941-52. doi: 10.3892/mmr.2018.8530

24. Hong L, Yu T, Xu H, Hou N, Cheng Q, Lai L, et al. Down-regulation of miR-378a-3p induces decidual cell apoptosis: a possible mechanism for early pregnancy loss. Hum Reprod. (2018) 33:11-22. doi: 10.1093/humrep/dex347

25. Sarno J, Schatz F, Huang SJ, Lockwood C, Taylor HS. Thrombin and interleukin-1beta decrease HOX gene expression in human first trimester decidual cells: implications for pregnancy loss. Mol Hum Reprod. (2009) 15:451-7. doi: 10.1093/molehr/gap030

26. Wicherek L, Klimek M, Czekierdowski A, Popiela TJ, Galazka K, Tetlak T, et al. The placental RCAS1 expression during stillbirth. Reprod Biol Endocrinol. (2005) 17:3-24. doi: 10.1186/1477-7827-3-24

27. Harris RA, Ferrari F, Ben-Shachar S, Wang X, Saade G, Van Den Veyver I, et al. Genome-wide array-based copy number profiling in human placentas from unexplained stillbirths. Prenat Diagn. (2011) 31:932944. doi: $10.1002 /$ pd.2817

28. Ferrari F, Facchinetti F, Yin H, Saade GR, Longo M. Singlenucleotide polymorphisms in genes involved in placental function and unexplained stillbirth. Am J Obstet Gynecol. (2012) 207:316.e1-7. doi: 10.1016/j.ajog.2012.06.030

29. Ernst LM, Rand CM, Bao R, Andrade J, Linn RL, Minturn L, et al. Stillbirth: genome-wide copy number variation profiling in archived placental umbilical cord samples with pathologic and clinical correlation. Placenta. (2015) 36:783-9. doi: 10.1016/j.placenta.2015.04.010

30. Silver RM, Saade GR, Thorsten V, Parker CB, Reddy UM, DrewsBotsch C, et al. Factor V Leiden, prothrombin G20210A, and methylene tetrahydrofolate reductase mutations and stillbirth: the stillbirth collaborative research network. Am J Obstetrics Gynecol. (2016) 215:468. doi: 10.1016/j.ajog.2016.04.026

31. Romagnuolo I, Sticchi E, Attanasio M, Grifoni E, Cioni G, Cellai AP, et al. Searching for a common mechanism for placenta-mediated pregnancy complications and cardiovascular disease: role of lipoprotein(a). Fertil Steril. (2016) 105:1287-1293.e3. doi: 10.1016/j.fertnstert.2016. 01.014

32. Maiti K, Sultana Z, Aitken RJ, Morris J, Park F, Andrew B, et al. Evidence that fetal death is associated with placental aging. Am J Obstet Gynecol. (2017) 217:441.e1-441.e14. doi: 10.1016/j.ajog.2017.06.015

33. Campbell J, Armstrong K, Palaniappan N, Maher E, Glancy M, Porteous $\mathrm{M}$, et al. In a genomic era, placental pathology still holds the key in the nondysmorphic stillbirth. Pediatr Dev Pathol. (2018) 21:308-18. doi: $10.1177 / 1093526617733373$ 
34. Park D-W, Lee S-K, Hong SR, Han A-R, Kwak-Kim J, Yang KM. Expression of Kisspeptin and its receptor GPR54 in the first trimester trophoblast of women with recurrent pregnancy loss. Am J Reprod Immunol. (2012) 67:1329. doi: 10.1111/j.1600-0897.2011.01073.x

35. Saunders RD, Nakajima ST, Rai SN, Pan J, Gercel-Taylor C, Taylor DD. Alterations in antibody subclass immune reactivity to trophoblast-derived fetal fibronectin and $\alpha 2$-macroglobulin in women with recurrent pregnancy loss. Am J Reprod Immunol. (2012) 68:438-49. doi: 10.1111/j.1600-0897.2012.01182.x

36. Wang ZC, Yunis EJ, De los Santos MJ, Xiao L, Anderson DJ, Hill JA. T helper 1-type immunity to trophoblast antigens in women with a history of recurrent pregnancy loss is associated with polymorphism of the IL1B promoter region. Genes Immun. (2002) 3:38-42. doi: 10.1038/sj.gene.6363812

37. Wang ZC, Hill JA, Yunis EJ, Xiao L, Anderson DJ. Maternal CD $46 \mathrm{H}^{*} 2$ and IL1B-511*1 homozygosity in T helper 1-type immunity to trophoblast antigens in recurrent pregnancy loss. Hum Reprod. (2006) 21:81822. doi: 10.1093/humrep/dei366

38. Masini S, Ticconi C, Gravina P, Tomassini M, Pietropolli A, Forte V, et al. Thrombin-activatable fibrinolysis inhibitor polymorphisms and recurrent pregnancy loss. Fertil Steril. (2009) 92:694-702. doi: 10.1016/j.fertnstert.2008.07.015

39. Eller AG, Branch DW, Nelson L, Porter TF, Silver RM. Vascular endothelial growth factor-A gene polymorphisms in women with recurrent pregnancy loss. J Reprod Immunol. (2011) 88:48-52. doi: 10.1016/j.jri.2010.06.159

40. Uusküla L, Rull K, Nagirnaja L, Laan M. Methylation allelic polymorphism (MAP) in chorionic gonadotropin beta5 (CGB5) and its association with pregnancy success. J Clin Endocrinol Metab. (2011) 96:E199207. doi: $10.1210 /$ jc.2010-1647

41. Mohammad Seyedhassani S, Houshmand M, Mehdi Kalantar S, Aflatoonian A, Modabber G, Hashemi-Gorji F, et al. BAX pro-apoptotic gene alterations in repeated pregnancy loss. Arch Med Sci. (2011) 7:11722. doi: 10.5114/aoms.2011.20614

42. Choi H-K, Choi BC, Lee S-H, Kim JW, Cha KY, Baek K-H. Expression of angiogenesis- and apoptosis-related genes in chorionic villi derived from recurrent pregnancy loss patients. Mol Reprod Dev. (2003) 66:2431. doi: $10.1002 / \mathrm{mrd} .10331$

43. Zhang Y, Zhang Y, Li C, Fu S, Yang C, Song Y, et al. NOD1 modulates decidual stromal cell function to maintain pregnancy in the early trimester. Cell Biochem Funct. (2019) 37:464-73. doi: 10.1002/cbf.3417

44. Kaare M, Ulander VM, Painter JN, Ahvenainen T, Kaaja R, Aittomäki $\mathrm{K}$. Variations in the thrombomodulin and endothelial protein $\mathrm{C}$ receptor genes in couples with recurrent miscarriage. Hum Reprod. (2007) 22:864-8. doi: 10.1093/humrep/del436

45. Ticconi C, Mancinelli F, Gravina P, Federici G, Piccione E, Bernardini S. Betafibrinogen G-455A polymorphisms and recurrent miscarriage. Gynecol Obstet Invest. (2011) 71:198-201. doi: 10.1159/000317522

46. Nair RR, Khanna A, Singh K. Role of inflammatory proteins S100A8 and S100A9 in pathophysiology of recurrent early pregnancy loss. Placenta. (2013) 34:824-7. doi: 10.1016/j.placenta.2013.06.307

47. Rogenhofer N, Engels L, Bogdanova N, Tüttelmann F, Thaler CJ, Markoff A. Independent association of the M2/ANXA5 haplotype with recurrent pregnancy loss (RPL) in PCOS patients. Metab Clin Exp. (2013) 62:105760. doi: 10.1016/j.metabol.2013.02.005

48. Jin $\mathrm{H}, \mathrm{Wu} \mathrm{J}$, Yang Q, Cai $\mathrm{Y}, \mathrm{He} \mathrm{W}$, Liu C. High mobility group box 1 protein polymorphism affects susceptibility to recurrent pregnancy loss by up-regulating gene expression in chorionic villi. J Assist Reprod Genet. (2015) 32:1123-8. doi: 10.1007/s10815-0150493-3

49. O’Hern Perfetto C, Fan X, Dahl S, Krieg S, Westphal LM, Bunker Lathi R, Nayak NR. Expression of interleukin-22 in decidua of patients with early pregnancy and unexplained recurrent pregnancy loss. J Assist Reprod Genet. (2015) 32:977-84. doi: 10.1007/s10815-015-0481-7

50. He X, Chen Q. Reduced expressions of connexin 43 and VEGF in the firsttrimester tissues from women with recurrent pregnancy loss. Reprod Biol Endocrinol. (2016) 14:46. doi: 10.1186/s12958-016-0179-4

51. Yan X, Wang L, Yan C, Zhang X, Hui L, Sheng Q, et al. Decreased expression of the vitamin D receptor in women with recurrent pregnancy loss. Arch Biochem Biophys. (2016) 606:128-33. doi: 10.1016/j.abb.2016.07.021
52. Sõber S, Rull K, Reiman M, Ilisson P, Mattila P, Laan M. RNA sequencing of chorionic villi from recurrent pregnancy loss patients reveals impaired function of basic nuclear and cellular machinery. Sci Rep. (2016) 6:38439. doi: $10.1038 /$ srep38439

53. Qiao Y, Wen J, Tang F, Martell S, Shomer N, Leung PCK, et al. Whole exome sequencing in recurrent early pregnancy loss. Mol Hum Reprod. (2016) 22:364-72. doi: 10.1093/molehr/gaw008

54. Quintero-Ronderos P, Mercier E, Gris J-C, Esteban-Perez C, MorenoOrtiz H, Fonseca DJ, et al. THBD sequence variants potentially related to recurrent pregnancy loss. Reprod Biol Endocrinol. (2017) 15:92. doi: 10.1186/s12958-017-0311-0

55. Quintero-Ronderos P, Mercier E, Fukuda M, González R, Suárez CF, Patarroyo MA, et al. Novel genes and mutations in patients affected by recurrent pregnancy loss. PLoS ONE. (2017) 12:e0186149. doi: 10.1371/journal.pone. 0186149

56. Shehab O, Tester DJ, Ackerman NC, Cowchock FS, Ackerman MJ. Whole genome sequencing identifies etiology of recurrent male intrauterine fetal death. Prenat Diagn. (2017) 37:1040-5. doi: 10.1002/p d. 5142

57. Li L, Choi BC, Ryoo JE, Song SJ, Pei CZ, Lee KY, Paek J, Baek KH. Opposing roles of inter- $\alpha$-trypsin inhibitor heavy chain 4 in recurrent pregnancy loss. EBioMedicine. (2018) 37:535-46. doi: 10.1016/j.ebiom.2018.10.029

58. Yu M, Du G, Xu Q, Huang Z, Huang X, Qin Y, et al. Integrated analysis of DNA methylome and transcriptome identified CREB5 as a novel risk gene contributing to recurrent pregnancy loss. EBioMedicine. (2018) 35:33444. doi: 10.1016/j.ebiom.2018.07.042

59. Papamitsou T, Toskas A, Papadopoulou K, Sioga A, Lakis S, Chatzistamatiou $\mathrm{M}$, et al. Immunohistochemical study of immunological markers: HLAG, CD16, CD25, CD56 and CD68 in placenta tissues in recurrent pregnancy loss. Histol Histopathol. (2014) 29:1047-55. doi: 10.14670/HH-29.1047

60. Pfeiffer KA, Fimmers R, Engels G, van der Ven H, van der Ven K. The HLA-G genotype is potentially associated with idiopathic recurrent spontaneous abortion. Mol Hum Reprod. (2001) 7:373-8. doi: 10.1093/molehr/ 7.4.373

61. Kaare M, Painter JN, Ulander VM, Kaaja R, Aittomäki K. Variations of the Amnionless gene in recurrent spontaneous abortions. Mol Hum Reprod. (2006) 12:25-9. doi: 10.1093/molehr/gah255

62. Agrawal D, Prakash S, Misra MK, Phadke SR, Agrawal S. Implication of HLA-G 5' upstream regulatory region polymorphisms in idiopathic recurrent spontaneous abortions. Reprod Biomed Online. (2015) 30:82-91. doi: 10.1016/j.rbmo.2014.09.015

63. Gharesi-Fard B, Zolghadri J, Kamali-Sarvestani E. Alteration in the expression of proteins in unexplained recurrent pregnancy loss compared with in the normal placenta. J Reprod Dev. (2014) 60:261-7. doi: 10.1262/jrd.2013-096

64. Alonso A, Soto I, Urgellés MF, Corte JR, Rodríguez MJ, Pinto CR. Acquired and inherited thrombophilia in women with unexplained fetal losses. Am J Obstet Gynecol. (2002) 187:133742. doi: $10.1067 / \mathrm{mob} .2002 .126849$

65. Mehandjiev TR, Tenno NM, Nakura Y, Georgiev TP, Minekawa R, Wakimoto $\mathrm{T}$, et al. Impact of maternal methylenetetrahydrofolate reductase C677T polymorphism on intervillous and decidual pathology with pregnancy loss. J Obstet Gynaecol Res. (2019) 45:78-85. doi: 10.1111/jog. 13798

66. Cochery-Nouvellon E, Chauleur C, Demattei C, Mercier E, Fabbro-Peray $\mathrm{P}$, Marès $\mathrm{P}$, et al. The A6936G polymorphism of the endothelial protein $\mathrm{C}$ receptor gene is associated with the risk of unexplained foetal loss in Mediterranean European couples. Thromb Haemost. (2009) 102:656667. doi: 10.1160/TH-09-04-0224

67. Nicolas G, Veltman JA. The role of de novo mutations in adultonset neurodegenerative disorders. Acta Neuropathol. (2019) 137:183207. doi: 10.1007/s00401-018-1939-3

68. Geraedts J. Chromosomal anomalies and recurrent miscarriage. Infertil Reproduct Med Clinic NA. (1996) 7:677-88.

69. Wilkins-Haug L. Genetic innovations and our understanding of stillbirth. Hum Genet. (2020) 21:1-2. doi: 10.1007/s00439-020-02146-2

70. Yates CL, Monaghan KG, Copenheaver D, Retterer K, Scuffins J, Kucera $\mathrm{CR}$, et al. Whole-exome sequencing on deceased fetuses with ultrasound 
anomalies: expanding our knowledge of genetic disease during fetal development. Genet Med. (2017) 19:1171-1178. doi: 10.1038/gim. 2017.31

71. Acuna-Hidalgo R, Veltman JA, Hoischen A. New insights into the generation and role of de novo mutations in health and disease. Genome Biol. (2016) 17:1-19. doi: 10.1186/s13059-016$1110-1$

Author Disclaimer: The content is solely the responsibility of the authors and does not necessarily represent the official views of the National Institutes of Health.

Conflict of Interest: The authors declare that the research was conducted in the absence of any commercial or financial relationships that could be construed as a potential conflict of interest.
Publisher's Note: All claims expressed in this article are solely those of the authors and do not necessarily represent those of their affiliated organizations, or those of the publisher, the editors and the reviewers. Any product that may be evaluated in this article, or claim that may be made by its manufacturer, is not guaranteed or endorsed by the publisher.

Copyright (๑) 2021 Carey, Blue, Varner, Page, Chaiyakunapruk, Quinlan, Branch, Silver and Workalemahu. This is an open-access article distributed under the terms of the Creative Commons Attribution License (CC BY). The use, distribution or reproduction in other forums is permitted, provided the original author(s) and the copyright owner(s) are credited and that the original publication in this journal is cited, in accordance with accepted academic practice. No use, distribution or reproduction is permitted which does not comply with these terms. 